Original Article

\title{
BIO-ANALYTICAL METHOD DEVELOPMENT AND VALIDATION FOR SIMULTANEOUS DETERMINATION OF LEDIPASVIR AND SOFOSBUVIR DRUGS IN HUMAN PLASMA BY RP-HPLC METHOD
}

\author{
BUYYA SHYAM SUNDER, ASHUTOSH KUMAR MITTAL* \\ Syngene International Limited, Bommasandra Industrial Area Phase-IV, Jigani Link Road, Bangalore, 560099, India \\ Email: ashutosh.mittal@syngeneinti.com
}

Received: 22 Jan 2018, Revised and Accepted: 08 Apr 2018

\section{ABSTRACT}

Objective: A novel, sensitive and accurate high-performance liquid chromatography with ultraviolet/visible light detection (HPLC-UV/VIS) method for the quantification of ledipasvir and Sofosbuvir in plasma was developed and validated.

Methods: The analytes were extracted by liquid-liquid extraction method and chromatograph using a mobile phase consisting of acetonitrile and buffer solution, Methanol and Acetonitrile in the ratio of 200:600:200 (v/v) using Oyster BDS RP-C18 column. The flow rate 1.0 ml/min and UV detection at $238 \mathrm{~nm}$ were employed. The retention time for Ledipasvir and Sofosbuvir was 4.61 and 9.09 min respectively. Linearity for ledipasvir and Sofosbuvir was found to be in the range of $250-2000 \mathrm{ng} / \mathrm{ml}$ for both drugs respectively. Intra-and inter-day precision was less than $2 \%$ coefficient of variation

Results: The method was validated as per the USFDA guidelines and the results were within the acceptance criteria for selectivity, sensitivity, linearity, precision, accuracy, recovery stability of the solution, the stability of solution in plasma and dilution integrity.

Conclusion: Majority of the HPLC method should be useful for monitoring human plasma drug concentrations, and pharmacokinetic studies in patients diagnosed with the Ledipasvir and Sofosbuvir formulations.

Keywords: Ledipasvir, Sofosbuvir, Bio-analytical, RP-HPLC, Plasma

(c) 2018 The Authors. Published by Innovare Academic Sciences Pvt Ltd. This is an open access article under the CC BY license (http://creativecommons.org/licenses/by/4.0/) DOI: http://dx.doi.org/10.22159/ijcpr.2018v10i3.27223

\section{INTRODUCTION}

Hepatitis C virus (HCV) one of the major global health problems. HCV infection is responsible for 3,50,000 death cases annually [1]. It is one of the top five death-causing diseases in the country. HCV infection is particularly a national problem in Egypt. The incidence rate reaches $14.5 \%$ among Egyptian population, which represents the highest prevalence of hepatitis $\mathrm{C}$ worldwide [2]. According to the egyptian ministry of health, 1,00,0000 new cases are identified each year [3]. Of particular note, the first all oral treatments, without the need for Ribavirin or pegIFNa injections, were recently approved: the combination pill, Harvoni TM (Ledipasvir, [4] NS5B inhibitor/ Sofosbuvir 1), a combination of Simeprevir (2) and Sofosbuvir (1) and Viekira PakTM, a combination of three DAAs and Ritonavir, i.e., Paritaprevir [5] (3) (NS3 protease inhibitor), several NS3 protease inhibitors Danoprevir (4), [6] and also Ledipasvir 5 (LED) known as GS-5885, is an NS5A inhibitor and antiviral against HCV (genotypes 1a and 1b)[7] fig. 1).

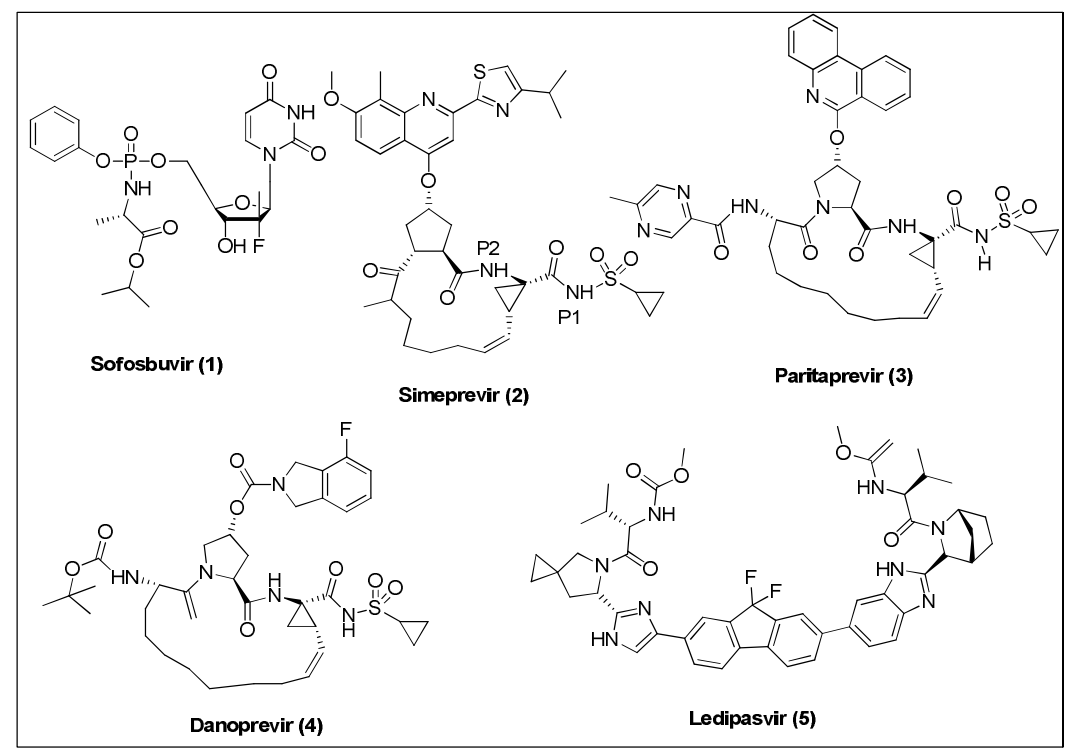

Fig. 1: Examples of approved drugs for HCV treatment: the HCV NS3/4a protease inhibitors 2, 3, 4 and the NS5B, NS5A polymerase inhibitor 1,5 respectively 
Ledipasvir, [methyl ((S)-1-((S)-6-(4-(9,9-difluoro-7-(2-((1R,3R,4R)2-((S)-2-((1-methoxyvinyl) amino)-3-methylbutanoyl)-2-azabicyclo [2.2.1] heptan-3-yl)-1H-benzo[d]imidazol-6-yl)-9H-fluoren-2-yl)-1Himidazol-2-yl)-5-azaspiro [2.4] heptan-5-yl)-3-methyl-1-oxobutan2 -yl) carbamate] is belongs to the class of organic compounds known as fluorenes used for the treatment of hepatitis C [8]. It acts against HCV and is categorized as a direct-acting antiviral agent (DAA). It is an inhibitor of the Hepatitis C Virus (HCV) NS5A protein which is required for viral RNA replication and assembly of HCV virions [9]. Sofosbuvir, IUPAC name is Isopropyl-(2S)-2-[[[( $2 R, 3 R$, $4 R, \quad 5 R)$-5-(2,4-dioxopyrimidin-1-yl)-4-fluoro-3-hydroxy-4-methyltetrahydro-furan-2-yl] methoxy-phenoxy-phosphoryl] amino] propanoate, and a nucleotide analog belongs to the class of organic compounds known as pyrimidine 2'-deoxyribonucleosides [10]. It is a pro-drug nucleotide analog used in combination therapy to treat chronic hepatitis $\mathrm{C}$ virus (HCV) infected patients with HCV genotype 1,2,3, or 4, and to treat HCV and HIV co-infected patients [11-13]. The combination therapy includes either ribavirin alone or ribavirin and peginterferon alfa. Sofosbuvir prevents HCV viral replication by binding to the two $\mathrm{Mg}^{2+}$ ions present in HCV NS5B polymerase's GDD active site motif [14].

Ledipasvir and Sofosbuvir combination, or Ledipasvir in combination with Sofosbuvir and Ribavirin, is indicated for the treatment of chronic hepatitis $\mathrm{C}(\mathrm{CHC})$ genotype 1 infection in adults [15]. The fixed-dose combination Ledipasvir-Sofosbuvir $(90 \mathrm{mg} / 400$ $\mathrm{mg}$ ) is indicated for treatment, with or without Ribavirin, for the treatment of patients with chronic hepatitis C genotypes $1,4,5$, and $6[16,17]$. Literature states that there are only two analytical methods have been described for analysis of Ledipasvir and Sofosbuvir in an individual by HPLC [18]. Due to high usage of Ledipasvir and Sofosbuvir combination for treatment of hepatitis C the present work is aimed to develop a bio-analytical method for combined analysis of Ledipasvir and Sofosbuvir in plasma.

\section{MATERIALS AND METHODS}

\section{Chemicals}

Analytically pure drugs were obtained as gift sample reputed pharmaceutical company. Methanol, acetonitrile, water (Merck, Mumbai, India) was of HPLC grade, while potassium dihydrogen phosphate, orthophosphoric acid and triethylamine used for the preparation of mobile phase.

\section{Equipment}

Chromatographic separation was performed on a PEAK chromatographic system equipped with LC-P7000 pump, UV detector UV7000 and the output signal was monitored and integrated by PEAK Chromatographic Software version 1.06. Oyster BDS RP-C18 column was used as stationary phase. Teccomp UV2301 double beam UV-Visible spectrophotometer was used to carry out spectral analysis and the data was recorded by Hitachi software. Denver electronic analytical balance (SI-234), Systronics digital pH meter was also used.

\section{Preparation pH 4.4 Acetate buffer (USP)}

$136 \mathrm{~g}$ of sodium acetate and $77 \mathrm{~g}$ of ammonium acetate are accurately weighed and dissolved in water and dilute to $1000 \mathrm{ml}$ with the same solvent. Then $250.0 \mathrm{ml}$ of glacial acetic acid is added and mixed well to get a buffer solution of $\mathrm{pH} 4.4$.

\section{Preparation of mobile phase}

Measure accurately Acetate buffer ( $\mathrm{pH}$ 4.4) buffer solution, Methanol and Acetonitrile in the ratio of 200:600:200 (v/v) and sonicate the solution for ten minutes mix the contents. The content was mixed and degassed using ultrasonic sonicater, and then it was filtered through $0.45 \mu$ nylon membrane filter paper using vacuum filtration set.

\section{Preparation of stock and standard solutions}

A stock solution of $1000 \mathrm{mcg} / \mathrm{ml}$ of Ledipasvir and Sofosbuvir prepared individually by accurately weighing $100 \mathrm{mg}$ of the standard drugs and was dissolved in $100 \mathrm{ml}$ of methanol to obtain a standard concentration of $1000 \mathrm{mcg} / \mathrm{ml}$. The solutions were filtered and were used as standard stock solutions. From the standard stock solution of $1000 \mathrm{mcg} / \mathrm{ml}, 1 \mathrm{ml}$ was further diluted to $100 \mathrm{ml}$ to get a working standard solution of $1000 \mathrm{ng} / \mathrm{ml}$. required dilutions were prepared from this working standard stock solution. Aliquots of a standard stock solution of Ledipasvir and Sofosbuvir were transferred using A-grade bulb pipettes into $100 \mathrm{ml}$ volumetric flasks and the solution was made up to volume with methanol to yield a final concentration of $250,500,750,1000,1250,1500,1750$, $2000 \mathrm{ng} / \mathrm{ml}$ individually.

\section{Rinsing solution}

7:3 ratios of methanol and Acetonitrile were used as rinsing solution. To this $70 \mathrm{ml}$ of methanol was mixed with $30 \mathrm{ml}$ of acetonitrile in a $100 \mathrm{ml}$ beaker. Mix the solution well and then it was filtered through membrane filter paper. The solution was used as rinsing solution to rinse useful things. The solution was stored at room temperature and used within $7 \mathrm{~d}$ from the date of preparation.

\section{Preparation of extraction solution}

Diethyl ether and dichloromethane in the ratio of $60: 40(\mathrm{v} / \mathrm{v})$ was used for the extraction of drugs from the biological matrix. $60 \mathrm{ml}$ of Diethyl ether was added to $40 \mathrm{ml}$ of dichloromethane. Mix the solution well and then it was filtered and used for the extraction. The solution was stored at room temperature and used within $7 \mathrm{~d}$ from the date of preparation.

\section{Extraction procedure}

The liquid-liquid extraction method was used to isolate both the standard drug's plasma. For this, $50 \mu \mathrm{l}$ of standard drug and $100 \mu \mathrm{l}$ of plasma sample (respective concentration) were added into labeled polypropylene tubes and vortexed briefly after that $2.5 \mathrm{ml}$ of methyl t-butyl ether was added and vortexed for approximately $10 \mathrm{~min}$ followed by centrifuged at $4000 \mathrm{rpm}$ for approximately $5 \mathrm{~min}$ at $20^{\circ} \mathrm{C}$. Supernatant from each sample was transferred to labeled vial tube and evaporated at $40{ }^{\circ} \mathrm{C}$ until dryness. These samples were reconstituted with $500 \mu \mathrm{l}$ of reconstitution solution [Diethyl ether and dichloromethane] and vortexed briefly, and then transferred the sample into a clean dry test tube and was used for analysis.

\section{HPLC chromatography conditions}

The HPLC isocratic elution was run with mobile phase buffer solution, Methanol and Acetonitrile in the ratio of 200:600:200 (v/v) at $\mathrm{pH} 4.4$ and $1 \mathrm{ml} / \mathrm{min}$ flow rate. The chromatographic separation was achieved on Oyster BDS RP-C18 $5 \mu \mathrm{m}, 250 \mathrm{~mm}$ X $4.6 \mathrm{~mm}$ i.d. column at $238 \mathrm{~nm}$ UV detector wavelength. The column was maintained at room temperature and an injection volume of $20 \mu \mathrm{l}$ was used. The mobile phase was filtered through $0.45 \mu \mathrm{m}$ Chrom Tech Nylon-66 filter for use.

\section{RESULTS AND DISCUSSION}

One of the most difficult task during the method development was to achieve a high and reproducible recovery from the solvent which is used for extraction of the drug and also difficult task to select such single extracting solvent from which both the drugs are extracted. Different solvents were tried for the extraction of Ledipasvir and Sofosbuvir from human plasma and extraction with methyl t-butyl ether which is reconstituted solution [Diethyl ether and dichloro methane] was exhibited good recovery. Under the optimal conditions (table 1) employed, the retention times were $4.61 \mathrm{~min}$ and 9.09 min for Ledipasvir Sofosbuvir respectively, with good peak shape and resolution (table 2, fig. 2, 3). The proposed chromategraphic conditions are validated according to the ICH and US-FDA guidelines [19-21].

\section{Selectivity and system suitability}

The selectivity of the method was evaluated by analyzing six independent drug-free human plasma samples with reference to potential interferences from endogenous and environmental constituents. In optimization, trials choose such method where plasma lots were found to be free of significant interferences. Resolution, tailing factor and theoretical plate's results were with the acceptable limit thus meets the system suitability criteria. 


\section{Calibration curve/linearity}

The Eight point calibration curve was constructed by plotting the peak response ratio of Ledipasvir and Sofosbuvir in plasma. Correlation of coefficients is 0.999 and 0.998 for Ledipasvir and Sofosbuvir respectively. Linearity's were found over the range 250, $500,750,1000,1250,15000,1750,2000 \mathrm{ng} / \mathrm{ml}$ for both Ledipasvir and Sofosbuvir. The lower limit of quantification was defined as lowest concentration in the calibration curve. The Ledipasvir and Sofosbuvir can be determined at LLOQ 200ng/ml. Data of calculated calibration standard concentration are shown in table 3 respectively and a representative calibration curve is shown in fig. 4 .

\section{Precision and accuracy}

The precision of the method was determined by repeatability and accuracy for set of quality control (QC) sample (low, mid, high) in replicate $(n=6)$. The precision was found to be in the range $(\% \mathrm{CV})$ of $0.861-0.580 \%, 1.388-0.513$ and $1.275-0.813 \%$ for LQC, MQC and $\mathrm{HQC}$ respectively. In this assay the inter-day, intra-day precision and accuracy values were within the acceptable range, it shows that the method is accurate and precise. The low percent relative standard deviation and percent relative error were within the acceptable limit. The results of precision and accuracy for the Ledipasvir and Sofosbuvir are shown in table 4, 5 and 6.

\section{Recovery}

Absolute recovery was calculated by comparing peak areas obtained from freshly prepared sample extracted with unextracted standard solutions of the same concentration. Recovery data were determined in triplicates at $750 \mathrm{ng} / \mathrm{ml}$. The recovery of Ledipasvir and Sofosbuvir for was found to be $87.467 \%, 85.491$ respectively (table 7).

\section{Ruggedness and robustness}

The ruggedness of the extraction procedure and the chromatographic method was evaluated by analysis at $750 \mathrm{ng} / \mathrm{ml}$ concentration by a different analyst. Within batch precision of the method was in the range of 101.2 to $102.6 \%$ and 100.4 to $102.3 \%$ for Ledipasvir and Sofosbuvir respectively. Robustness results are achieved in the range of 0.136 to $0.179 \%$ and 0.134 to $0.89 \%$ of the change in the results.

\section{Stability}

Stabilities of the samples were determined in various phases of the method. The stability studies include stock solution stability, freeze-thaw stability, in-injector stability, bench-top stability and long-term stability. All the above stability studies indicate that the samples in various phases were within the acceptance limits. The concentration of the freeze-thaw samples was found to be $91.9-104.3 \%$ of the nominal concentration for Ledipasvir and $91.5-101.2 \%$ for Sofosbuvir, indicating the stability of the analytes over three freeze-thaw cycles. For the bench top stability, the back-calculated concentration against freshly spiked calibration standards was found to be 93.6 to $100.1 \%$ of the nominal concentration for Ledipasvir and 92.7 to $100.3 \%$ Sofosbuvir. The concentration of the long term-stability samples ranged between 87.3 to $99.4 \%$ and 84.8 to $98.9 \%$ of the nominal value, respectively, for Ledipasvir and Sofosbuvir. The long-term stability duration was calculated as the date of analysis of QC samples, less the date of preparation of the stability QC samples.
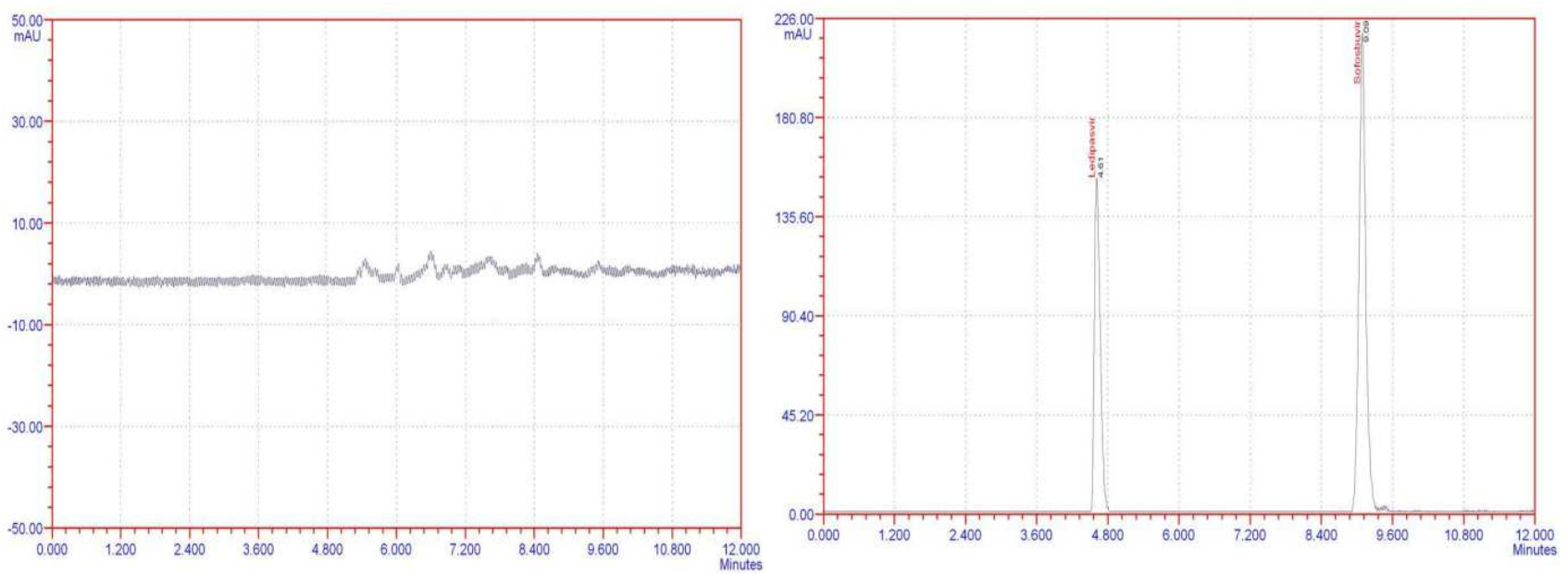

Fig. 2: Blank and standard chromatograms of ledipasvir and sofosbuvir

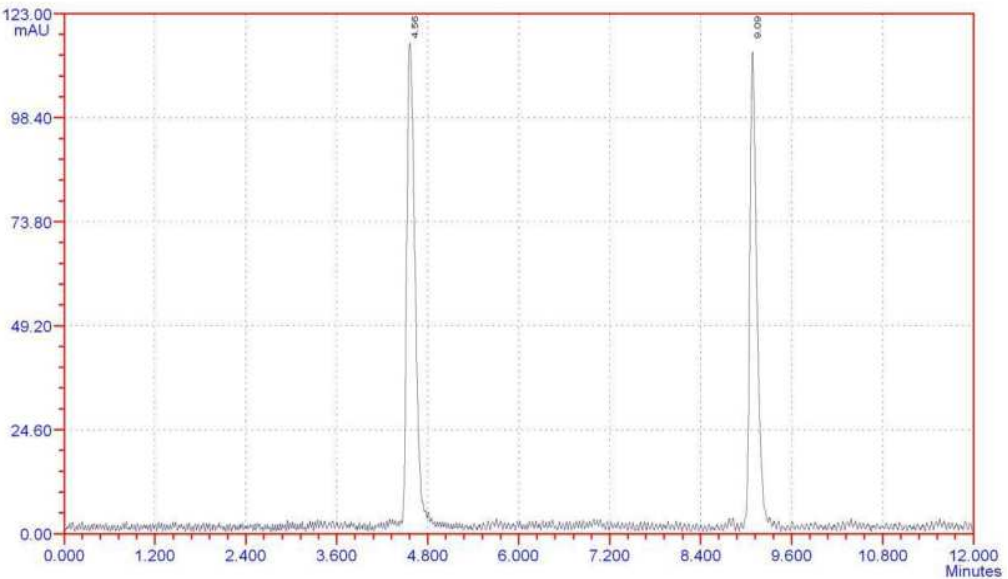

Fig. 3: Sample chromatograms of Ledipasvir and Sofosbuvir 
Table 3: Plasma spiked calibration curve results

\begin{tabular}{lllll}
\hline Test & Sample ID & Ledipasvir & Sofosbuvir \\
\cline { 3 - 5 } & & Concentration prepared & Area obtained & Concentration prepared \\
\hline PSCC & PSCC01 & $250 \mathrm{ng} / \mathrm{ml}$ & 52563 & $250 \mathrm{ng} / \mathrm{ml}$ \\
& PSCC02 & $500 \mathrm{ng} / \mathrm{ml}$ & 80925 & $500 \mathrm{ng} / \mathrm{ml}$ \\
& PSCC03 & $750 \mathrm{ng} / \mathrm{ml}$ & 104220 & $750 \mathrm{ng} / \mathrm{ml}$ \\
& PSCC04 & $1000 \mathrm{ng} / \mathrm{ml}$ & 134956 & $1000 \mathrm{ng} / \mathrm{ml}$ \\
& PSCC05 & $1250 \mathrm{ng} / \mathrm{ml}$ & 157489 & $1250 \mathrm{ng} / \mathrm{ml}$ \\
& PSCC06 & $1500 \mathrm{ng} / \mathrm{ml}$ & 187484 & $1500 \mathrm{ng} / \mathrm{ml}$ \\
& PSCC07 & $1750 \mathrm{ng} / \mathrm{ml}$ & 209997 & $1750 \mathrm{ng} / \mathrm{ml}$ \\
N & PSCC08 & $2000 \mathrm{ng} / \mathrm{ml}$ & 239272 & $2000 \mathrm{ng} / \mathrm{ml}$ \\
Slope & & 8 & & 8 \\
Intercept & 105.9 & & 195.0 \\
$\mathrm{r}^{2}$ & & 26686 & & 11142 \\
\hline
\end{tabular}

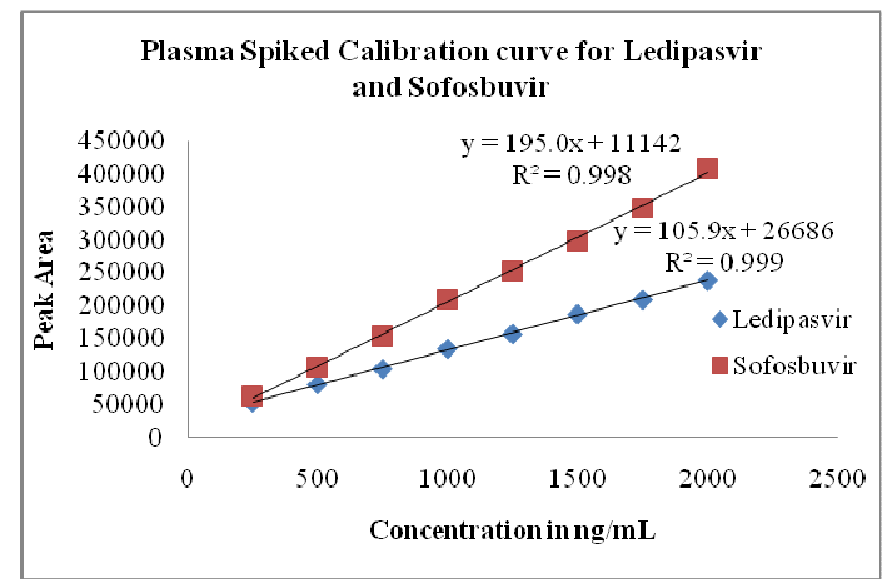

Fig. 4: Plasma spiked calibration graph

Table 4: Results of precision and accuracy at LQC

\begin{tabular}{|c|c|c|c|c|c|}
\hline \multicolumn{6}{|l|}{$P$ and $A$ at $L Q C$} \\
\hline \multirow[t]{2}{*}{ S. No. } & \multirow[t]{2}{*}{ Sample ID } & \multicolumn{2}{|l|}{ Ledipasvir } & \multicolumn{2}{|l|}{ Sofosbuvir } \\
\hline & & Area obtained & $\%$ accuracy & Area obtained & \% accuracy \\
\hline \multirow[t]{6}{*}{$P$ and $A$ at $L Q C$} & PA001 & 52326 & 99.54911 & 63761 & 100.6615 \\
\hline & PA002 & 51615 & 98.19645 & 62699 & 98.98488 \\
\hline & PA003 & 52802 & 100.4547 & 63423 & 100.1279 \\
\hline & PA004 & 52324 & 99.54531 & 63184 & 99.75056 \\
\hline & PA005 & 52814 & 100.4775 & 63575 & 100.3678 \\
\hline & PA006 & 52648 & 100.1617 & 63356 & 100.0221 \\
\hline Nominal Conc. & & $250 \mathrm{ng} / \mathrm{ml}$ & & $250 \mathrm{ng} / \mathrm{ml}$ & \\
\hline & & 6 & & 6 & \\
\hline Average & & 451.488 & 0.859 & 367.297 & 0.580 \\
\hline SD & & 52421.5 & 99.731 & 63333 & 99.986 \\
\hline$\% \mathrm{CV}$ & & 0.861 & 0.861 & 0.580 & 0.580 \\
\hline Accuracy (\%) & & 99.731 & & 99.986 & \\
\hline
\end{tabular}

Table 5: Results of precision and accuracy at MQC

\begin{tabular}{|c|c|c|c|c|c|}
\hline \multicolumn{6}{|l|}{$P$ and $A$ at $M Q C$} \\
\hline \multirow[t]{2}{*}{ S. No. } & \multirow[t]{2}{*}{ Sample ID } & \multicolumn{2}{|l|}{ Ledipasvir } & \multicolumn{2}{|l|}{ Sofosbuvir } \\
\hline & & Area obtained & \% accuracy & Area obtained & \% accuracy \\
\hline & PA007 & 104220 & 100 & 154431 & 100 \\
\hline \multirow[t]{5}{*}{$\mathrm{P}$ and $\mathrm{A}$ at $\mathrm{MQC}$} & PA008 & 104907 & 100.6592 & 155014 & 100.3775 \\
\hline & PA009 & 103429 & 99.24103 & 156648 & 101.4356 \\
\hline & PA010 & 101356 & 97.25197 & 154638 & 100.134 \\
\hline & PA011 & 102246 & 98.10593 & 155211 & 100.5051 \\
\hline & PA012 & 104786 & 100.5431 & 155582 & 100.7453 \\
\hline $\begin{array}{l}\text { Nominal Conc. } \\
\mathrm{N}\end{array}$ & & $\begin{array}{l}750 \mathrm{ng} / \mathrm{ml} \\
6\end{array}$ & & $\begin{array}{l}750 \mathrm{ng} / \mathrm{ml} \\
6\end{array}$ & \\
\hline Average & & 1437.054 & 1.379 & 795.871 & 0.515 \\
\hline SD & & 103490.7 & 99.300 & 155254 & 100.533 \\
\hline$\% \mathrm{CV}$ & & 1.388 & 1.388 & 0.513 & 0.513 \\
\hline Accuracy (\%) & & 99.300 & & 100.533 & \\
\hline
\end{tabular}


Table 6: Results of precision and accuracy at HQC

\begin{tabular}{|c|c|c|c|c|c|}
\hline \multicolumn{6}{|l|}{$P$ and $A$ at $H Q C$} \\
\hline \multirow[t]{2}{*}{ S. No. } & \multirow[t]{2}{*}{ Sample ID } & \multicolumn{2}{|l|}{ Ledipasvir } & \multicolumn{2}{|l|}{ Sofosbuvir } \\
\hline & & Area obtained & \% Accuracy & Area obtained & \% Accuracy \\
\hline \multirow{6}{*}{$\mathrm{P}$ and $\mathrm{A}$ at $\mathrm{HQC}$} & PA013 & 236257 & 98.73993 & 407011 & 99.45606 \\
\hline & PA014 & 235011 & 98.21918 & 407428 & 99.55796 \\
\hline & PA015 & 235109 & 98.26014 & 405325 & 99.04407 \\
\hline & PA016 & 237572 & 99.28951 & 407267 & 99.51862 \\
\hline & PA017 & 238177 & 99.54236 & 407836 & 99.65766 \\
\hline & PA018 & 229776 & 96.03129 & 399179 & 97.54226 \\
\hline Nominal Conc. & & $2000 \mathrm{ng} / \mathrm{ml}$ & & $2000 \mathrm{ng} / \mathrm{ml}$ & \\
\hline $\mathrm{N}$ & & 6 & & 6 & \\
\hline Average & & 2999.594 & 1.254 & 3297.963 & 0.805881 \\
\hline SD & & 235317 & 98.347 & 405674.3 & 99.129 \\
\hline$\% \mathrm{CV}$ & & 1.275 & 1.275 & 0.813 & 0.813 \\
\hline Accuracy (\%) & & 98.347 & & 99.129 & \\
\hline
\end{tabular}

Table 7: Results of plasma spiked recovery

\begin{tabular}{|c|c|c|c|c|c|}
\hline \multicolumn{6}{|c|}{ Plasma spiked recovery } \\
\hline \multirow[t]{2}{*}{ Test } & \multirow[t]{2}{*}{ Sample ID } & \multicolumn{2}{|l|}{ Ledipasvir } & \multicolumn{2}{|l|}{ Sofosbuvir } \\
\hline & & Area obtained & $\%$ recovery & Area obtained & $\%$ recovery \\
\hline \multirow{6}{*}{ PSR at MQC } & PSR001 & 107387 & 87.01222 & 153329 & 84.71964 \\
\hline & PSR002 & 108486 & 87.9027 & 155246 & 85.77885 \\
\hline & PSR003 & 108193 & 87.66529 & 154568 & 85.40423 \\
\hline & PSR004 & 107575 & 87.16455 & 155693 & 86.02584 \\
\hline & PSR005 & 107795 & 87.34281 & 154431 & 85.32854 \\
\hline & PSR006 & 108252 & 87.7131 & 155087 & 85.691 \\
\hline Nominal Conc. & & $750 \mathrm{ng} / \mathrm{ml}$ & & $750 \mathrm{ng} / \mathrm{ml}$ & \\
\hline $\mathrm{N}$ & & 6 & & 6 & \\
\hline Average & & 428.753 & 0.347 & 824.549 & 0.456 \\
\hline SD & & 107948 & 87.467 & 154725.7 & 85.491 \\
\hline$\% \mathrm{CV}$ & & 0.397 & 0.397 & 0.533 & 0.533 \\
\hline Recovery (\%) & & 87.467 & & 85.491 & \\
\hline
\end{tabular}

\section{CONCLUSION}

In the proposed study, the sensitive isocratic RP-HPLC method has been developed for simultaneous analysis of Ledipasvir and Sofosbuvir in plasma. The developed method was validated and was found to be novel, simple, sensitive, and precise. As the precision accuracy and robustness are a concern the \% RSD is less than 2 which is within range of ICH guidelines. Since, for preparation of plasma samples, the developed method involves direct estimation (precipitation of plasma protein by organic solvents) which is simple, cheap, accurate and easy in comparison to solid phase extraction or liquid-liquid extraction. So this HPLC method should be useful for monitoring plasma drug concentrations, and pharmacokinetic studies in patients diagnosed with the Ledipasvir and Sofosbuvir formulations.

\section{ACKNOWLEDGMENT}

One of the Author (BSS) is thankful to our Research Supervisor Dr. Ashutosh Kumar Mitta for providing us required facilities and motivation for completion of the research work. We also extend our gratitude towards Department of Chemistry (CEH, CCST), JNT University, Hyderabad.

\section{AUTHORS CONTRIBUTIONS}

All the author have contributed equally

\section{CONFLICT OF INTERESTS}

The authors declare no conflict of interest.

\section{REFERENCES}

1. Childs Kean LM, Hand EO. Simeprevir and sofosbuvir for treatment of chronic hepatitis C infection. Clin Ther 2015; 37:243-67.

2. Guerra J, Garenne M, Mohamed MK, Fontanet A. HCV burden of infection in Egypt: results from a nationwide survey. J Viral Hepat 2012;19:560-7.
3. Yahia M. Global health: a uniquely Egyptian epidemic. Nature 2011;474:S12-S13.

4. Guofeng Cheng, Yang Tian, Brian Doehle, Betty Peng, Amoreena Corsa, Yu-Jen Lee, et al. In vitro antiviral activity and resistance profile characterization of the hepatitis C virus NS5A inhibitor ledipasvir. Antimicrob Agents Chemother 2016;60:1847-53.

5. Carrion AF, Gutierrez J, Martin P. New antiviral agents for the treatment of hepatitis C: ABT-450. Expert Opin Pharmacother 2014;15:711-6.

6. Jiang Y, Andrews SW, Condroski KR, Buckman B, Serebryany V, Wenglowsky $\mathrm{S}$, et al. Discovery of danoprevir (ITMN191/R7227), a highly selective and potent inhibitor of hepatitis C virus (HCV) NS3/4A protease. J Med Chem 2014;57:1753-69.

7. Rose L, Bias TE, Mathias CB, Trooskin SB, Fong JJ. Sofosbuvir: a nucleotide NS5B inhibitor for the treatment of chronic hepatitis C infection. Ann Pharmacother 2014;48:1019-29.

8. Afdhal N, Zeuzem S, Kwo P, Chojkier M, Gitlin N, Puoti M, et al. Ledipasvir and sofosbuvir for untreated HCV genotype 1 infection. New England J Med 2014;370:1889-98.

9. Henderson JA, Bilimoria D, Bubenik M, Cadilhac C, Cottrell KM, Denis F, et al. Synthesis and evaluation of NS5A inhibitors containing diverse heteroaromatic cores. Bioorg Med Chem Lett 25;2015:948-51.

10. Asselah T. Sofosbuvir for the treatment of hepatitis $C$ virus. Expert Opin Pharmacother 2014;15:121-30.

11. Fung A, Jin Z, Dyatkina N, Wang G, Beigelman L, Deval J. Efficiency of incorporation and chain termination determines the inhibition potency of 2'-modified nucleotide analogs against hepatitis C virus polymerase. Antimicrob Agents Chemother 2014;58:3636-45.

12. L Carey. What is the role of Sofosbuvir in treating hepatitis $C$ infection. JAAPA 2015;28:16-9.

13. Molina JM, Orkin C, Iser DM, Zamora FX, Nelson M, Stephan C, et al. Sofosbuvir plus Ribavirin for treatment of hepatitis $\mathrm{C}$ virus in patients co-infected with HIV (PHOTON-2): a multicentre, openlabel, non-randomised, phase 3 study. Lancet 2015;385:1098-106. 
14. Sofia MJ, Bao D, Chang W, Du J, Nagarathnam D, Rachakonda S, et al. Discovery of a $\beta-\mathrm{d}-2^{\prime}$-deoxy-2'- $\alpha$-fluoro-2'- $\beta$-Cmethyluridine nucleotide prodrug (PSI-7977) for the treatment of hepatitis C virus. J Med Chem 2010;53:7202-18.

15. Kumari R, Nguyen MH. Fixed-dose combination of sofosbuvir and ledipasvir for the treatment of chronic hepatitis C genotype 1. Expert Opin Pharmacother 2015;16:739-48.

16. Younossi ZM, Stepanova M, Marcellin P, Afdhal N, Kowdley $\mathrm{KV}$, Zeuzem S, et al. Treatment with ledipasvir and Sofosbuvir improves patient-reported outcomes: results from the ION$1,-2$, and-3 clinical trials. Treatment with ledipasvir and sofosbuvir improves patient-reported outcomes: Results from the ION-1,-2, and-3 clinical trials. Hepatology 2015; 61:1798-808
17. Osinusi A, Townsend K, Kohli A, Nelson A, Seamon C, Meissner $\mathrm{EG}$, et al. Virologic response following combined ledipasvir and sofosbuvir administration in patients with HCV genotype 1 and HIV co-infection. JAMA 2015;313:1232-9.

18. Mohan Vikas P, Satyanarayana T, Vinod Kumar D, Mounika E, Sri Latha M, Anusha R, et al. Development and validation of new RP-HPLC method for the determination of Sofosbuvir in pure form. World J Pharm Pharm Sci 2006;5:775-81.

19. Food and Drug Administration. Guidance for industry; Bionalytical Method Validation, Center for Drug Evaluation and Research; 2001.

20. International Conference on Harmonization (ICH). Validation of Analytical Methods: Definitions and Terminology. ICH Q2 A; 1994.

21. International Conference on Harmonization (ICH). Validation of Analytical Methods: Methodology. ICH Q2 B; 1996. 